\title{
Application of artificial neural network in sizing a stand-alone photovoltaic system: a review
}

\author{
Ahmad Fateh Mohamad Nor, Suriana Salimin, Mohd Noor Abdullah, Muhammad Nafis Ismail \\ Green and Sustainable Energy (GSEnergy) Focus Group, Faculty of Electrical and Electronic Engineering, \\ Universiti Tun Hussein Onn Malaysia, Malaysia
}

\begin{tabular}{l}
\hline Article Info \\
\hline Article history: \\
Received Aug 19, 2019 \\
Revised Oct 27, 2019 \\
Accepted Nov 25, 2019 \\
\hline
\end{tabular}

Keywords:

Artificial neural network

System sizing

Renewable energy

Solar electricity

Stand-alone PV system

\begin{abstract}
Artificial Neural Network (ANN) techniques are becoming useful in the current era due to the vast development of the current computer technologies. ANN has been used in various fields especially in the field of science and technology. One of the advantage that makes ANN so interesting is the ANN's ability to learn the input and output relationship even though the relationship is non-linear. In addition, ANN is also useful for modelling, optimization, prediction, forecasting, and controlling systems. The main objective of this paper is to present a review of the ANN techniques for sizing a stand-alone photovoltaic (PV) system. The review in this paper shows the potential of ANN as a design tool for a stand-alone PV. In addition, ANN is very useful to improve the sizing process of the stand-alone PV system. The sizing process is of paramount importance to a stand-alone PV system in order to make sure the system can generate ample electrical energy to supply the load demand.
\end{abstract}

This is an open access article under the CC BY-SA license.

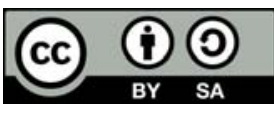

\section{Corresponding Author:}

Ahmad Fateh Mohamad Nor,

Green and Sustainable Energy (GSEnergy) Focus Group,

Faculty of Electrical and Electronic Engineering,

Universiti Tun Hussein Onn Malaysia, 86400 Parit Raja, Batu Pahat, Johor, Malaysia.

Email: afateh@uthm.edu.my

\section{INTRODUCTION}

The amount of electricity generated from renewable resources such as solar energy has increased annually for the past decade. It has been expected that the generation of electricity from photovoltaic (PV) technologies can reach more than $900 \mathrm{MW}$ [1-4]. This situation is due to the effect of global warming and the critical depletion of fossil fuel and natural gases that have been the main source of generating electricity all this time [5-7]. The dependency on fossil fuel and natural gasses in generating electricity resulted in greenhouse gas emissions. Hence, PV technology is a popular option of generating electricity because of its advantages of cleanliness and sufficiency [8]. Generally, PV system can be divided into two types which are grid-connected PV system and stand-alone PV system. A grid-connected PV system is when the building is being supplied by both PV and grid. The consumers can use the PV to power electrical appliances as well as selling excess PV electricity to the grid [9]. A stand-alone PV system on the other hand refers to an electrical load that is being powered completely by the PV system. A simple and basic stand-alone PV system can be done by connecting the PV panel to the load like DC motor. This simple PV system is usually use for powering water pumping system in remote areas [10]. A stand-alone PV system is more suitable to power houses or buildings in remote areas where the cost of bringing the grid is very high [11-13]. The most important thing in PV system is the sizing of the PV system. Sizing a stand-alone PV system is more crucial than sizing grid-connected PV system. This is due to the fact that every component in the stand-alone PV 
system must be sized very carefully since the electricity is 100 percent rely on the PV system. Any mistake in sizing the PV system can cause insufficient electrical power to supply the load requirements [14, 15]. The methodology of sizing PV system involves a number of calculations and procedures. These calculations and procedures of sizing the PV system can be time consuming and might also affect the accuracy of the sizing outcome. In order to make the PV sizing procedure easier and less time consuming, a number of researchers have come out with a variety of PV sizing method including the application of Artificial Neural Network (ANN) $[11,14,16-20]$. The main purpose of this paper is to present a review of the application of ANN in sizing a stand-alone PV system.

\section{SIZING A STAND-ALONE PV SYSTEM}

A stand-alone PV system can be well-defined as an electrical system that only consumes PV modules as the sole electrical power source. The main objective of the PV system's sizing procedure is to make sure that the electrical power produced by the PV system is adequate to supply the electrical load requirement [14]. The sizing procedure consist of a number of steps. Before starting the sizing procedure, the accurate peak sunshine data need to be known. This data can be obtained from the local meteorological department website etc. The peak sunshine data is very important because besides different locations have different peak sunshine data, the peak sunshine hours per day as well as the solar irradiation will affect the output of every PV panel [21].

The first step is a detailed electrical load analysis. Load analysis consist of the accumulation of the total electrical energy used in a specific period of time. Usually, the loads for stand-alone PV system are almost constant and only have small changes. If the load is variable throughout the day, then the highest value of that load should be taken into account. Another very important data that is needed is the load's operating time. This is due to the electrical loads rarely operate at the same time. For example, the lights are only used during nighttime, while the kettle is usually used early in the morning or evening. The operating time of load is the total number of hours per day that the load is operating. Not all loads are being used every day. For example, a washing machine operates for 2 hours every week has an equivalent operating time of 0.29 hour per day [14, 22-24].

The following steps after load analysis are basically regarding the sizing of every components in the stand-alone PV system. A stand-alone PV system consists of PV panel or PV array, inverter, solar charge controller and batteries $[15,25,26]$. The configuration of a standard stand-alone PV system is depicted in Figure 1. PV array will convert sunlight to DC electricity [27]. The required current and voltage that must be produced by the PV array need to be determined depends by the load demand (obtained from load analysis). This electricity will charge the battery bank. The solar charge controller acts to prevent the battery from being overcharged. Finally, inverter is used to convert DC produced by the PV panel/array from the battery bank to AC electricity [9].

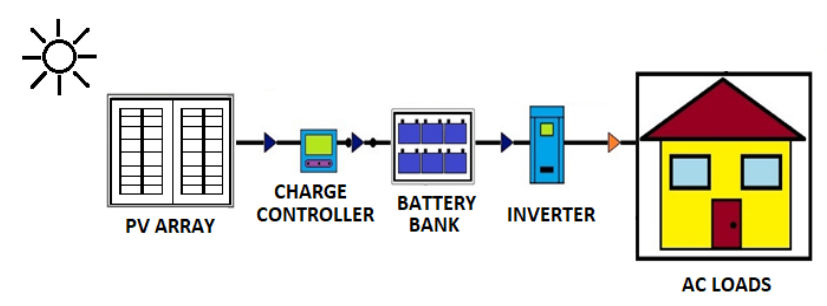

Figure 1. Configuration of a stand-alone PV system

In terms of sizing the charge controller, one has to make sure that the charge controller should be rated at least $125 \%$ of the maximum current from the PV array [14, 23]. This is to take into account the changes that might occurred in current value from the PV array. Another crucial part is sizing the charge controller is to make sure that the charge controller is able to operate with the battery system voltage. For instance, if the battery system voltage is $12 \mathrm{~V}$, then a charge controller with a voltage rating of $12 \mathrm{~V}$ should be selected.A battery bank is a number of batteries are being connected together whether in parallel, in series or both. At this step, the required ampere hour and system voltage of the battery bank is determined. Usually, the system voltage of the battery bank is determined according to the size of the system's power. Usually 12 $\mathrm{V}$ or $24 \mathrm{~V}$ battery bank voltage is used. Battery bank is sized to store enough energy to supply the loads requirement [23]. Finally, the inverter need to be sized so that it is able to supply at least the same amount of Application of artificial neural network in sizing a stand-alone photovoltaic ... (Ahmad Fateh Mohamad Nor) 
power as the total AC power demand. Nonetheless it is highly suggested that the size of the inverter have to be a bit higher than the total AC power demand by 10 to $40 \%$. Another vital part in sizing the inverter is that the inverter's output voltage must be same with the AC system voltage. For example if the AC system voltage is $240 \mathrm{VAC}$ then the inverter output voltage must also be $240 \mathrm{VAC}$. On the other hand, the DC input voltage of the inverter must equal with the battery system voltage [23].

\section{ARTIFICIAL NEURAL NETWORK}

Artificial Neural Network or ANN is a method that adapts the neuron system in the human brain into solving engineering or technology problem such as prediction values, classification, observation etc. ANN is very useful for modelling or predicting even though the input output data relationship is unknown [28-32]. A simple configuration of ANN is built up of three layers. The first layer is also known as input layer. This is where the data that has been selected as input is inserted into the ANN configuration. The second layer is known as the hidden layer. The second layer consist of neurons, weights as the synapses that connect all the neurons together. The third layer is the final and output layer that give away the processed data or the result from the ANN configuration [33]. ANN can be configured into a number of different configurations. Nevertheless, the most common and broadly used ANN configuration is the multilayer perceptron with back propagation [17]. It is called back propagation because the error between the predicted outputs from ANN with the target will be sent back to the hidden layer for weight adjustment [34]. Figure 2 [35] shows the configuration of the multilayer perceptron with back propagation network. Due to the current computer technology, ANN has been widely applied in various engineering fields including the PV field [36-39].

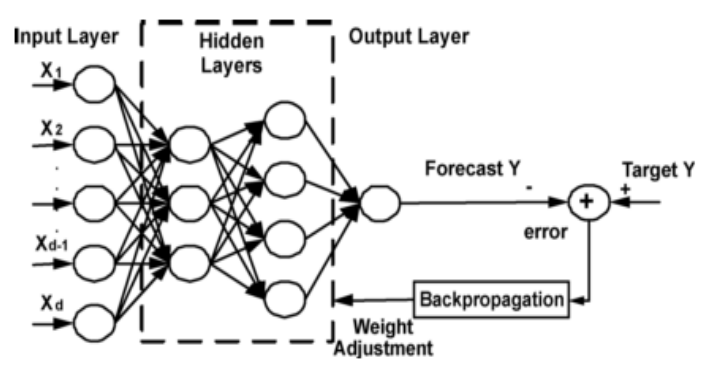

Figure 2. Configuration of the multilayer perceptron with back propagation of ANN

\section{APPLICATION OF ANN IN SIZING A STAND-ALONE PV SYSTEM}

In this section, the literature review on the application of ANN in sizing a stand-alone PV system are presented. The literature are selected based on the application of ANN in various aspect of PV system sizing. The aspects include the sizing of the PV system's components such as PV panels, batteries etc, the prediction of load power, the prediction of the electrical power that is able to be generated by the PV system, finding suitable tilt angle and so on.

One of the advantage of ANN that makes ANN suitable for sizing a PV system is that ANN has the ability to learn the connection between the input and output parameters. ANN can be used to achieve that by learning the previous recorded data [17]. This is also known as ANN training data. ANN acts like a "black box" where in this "black box" the learning and training process take place. Previous researcher work in [17] has applied ANN to predict the sizing coefficient of a stand-alone PV system. In this paper, a number of different ANN configurations are tested compared. The result showed that ANN configuration that consists of one hidden layer with 8 neurons gave the most accurate result. In addition, the ANN model developed in this paper is very suitable and fits North African countries such as Algeria. From there, an amount of research area can be done in order for this system to work in other countries especially Malaysia. This is due to the fact that the climate of Malaysia is very different that the climate of North African countries. The climate especially the amount of solar radiation have a great impact of the amount of electricity that the can be generated by the PV system. The findings in [40] have also shown that ANN configuration of one hidden layer with 8 neurons gave the most accurate output values. However, this does not mean that 8 number of neuron is the best number for every ANN configuration. This is because that the number of neuron varies from one ANN configuration to another depending on the type of data, size of data, initial weight value etc.

Int J Pow Elec \& Dri Syst Vol. 11, No. 1, Mar 2020 : 342 - 349 
The researchers in [20] has stated that ANN has been widely used in the field of renewable energy such as the sizing of PV system in remote areas. They have also successfully applied ANN to predict the sizing coefficient of a PV system. Also in this paper, they have improve the training system of the ANN by combining it with genetic algorithm (GA). The results have proved that the improved the ANN structure is able to predict the sizing coefficient of a PV system sizing curve with less initial information. The results from this paper have proved the advantage of ANN which it can learn or discover the relationship between the input and the target values even though the relationship is not clear or less informative. Other than that, the combination of ANN and GA has opened a huge research area. This can be applied in various PV application especially in the field of sizing a stand-alone PV system.

ANN in [41] has been applied to forecast solar irradiation and load power consumption for the PV system. They have used and compared a number of different configurations such as different number of layers, different set of inputs and different number of hidden neurons. This research has found out that the different configurations will give effect to the ANN prediction's accuracy. Different configurations can be used to improve accuracy values. However, the method of determining the best or suitable ANN configuration is yet to be discovered. This is because, as mentioned previously, different ANN configuration varies from one application to another. Hence, a wide research area on this topic is available to be explored. Ceylan et al. in [42] have used ANN to predict the efficiency of PV module for all regions in Turkey. The ANN configuration consists of the measured solar radiation and measured PV module ambient air temperatures as the inputs. While the ANN output is the PV module back side temperatures. PV modules temperature were chosen as the output because PV modules temperature has great impact in the efficiency of a PV system. The authors also have stated in this research work that ANN has been widely used to predict the efficiency and maximum power of the PV system.

Baptista et al. in [37] have applied ANN to predict the electrical energy production by a PV system. The prediction of electrical energy production by a PV system is very important in the sizing process for cost and system efficiency. The ANN used consists of three layers which are the input layer, hidden layer and output layer. The authors have raised one of the problem of applying ANN is the determination of number of hidden neurons. This is because there are no specific methods to identify the correct number of hidden neurons for each ANN configurations. Hence, this paper investigates two different methods to determine the number of hidden neurons. Those methods are Kolmogorov's Theorem and rule of thumb. This research work has concluded that the Kolmogorov's Theorem gave better results compared to the rule of thumb. In addition, this paper has successfully applied ANN to the field that is most related to PV sizing which is the energy that can be produced by the PV system. This technique can be further expanded into predicting the output power from other PV components such as battery banks etc.

Arun in [43] has developed a two-stage ANN configuration for predict the sizing curve for the stand-alone PV system in isolated areas in southern India. The first stage of the ANN configuration consists of the geographical coordinates of the location as the inputs. The outputs for this first stage are the minimum regulated PV array rating and the corresponding regulated battery capacity. In the second stage of the ANN configuration, the geographical coordinates and the standardized PV array ratings are being selected as the inputs, while the corresponding standardized storage capacities are selected as the outputs. This technique can be further expanded into multiple stage of ANN configuration. Other than that, this research also can be explored more using Malaysia's climate.

Chatterjee and Keyhani in [44] have implemented ANN to predict the ideal tilt angle of PV array at a specified location. This is to predict the amount of electrical energy generated from the PV array. The tilt angle of the PV array is very important in order to make sure the PV array is able to generate maximum electricity that the PV array is able to. Not only that, the tilt angle of the PV array can allow the rain water to flow when raining. This research work has concluded that ANN has the ability to learn the nonlinear relationship between the PV array tilt angles, latitude, ground reflectivity with the solar irradiation received without any complex analytical method. Nevertheless, the identification of the tilt angle of the PV module is very crucial in areas which is located closer to the earth's poles such as the European countries and Australia. For countries like Malaysia which is located near to the equator, the tilt angle is not much an issue since the location of the sun is more less the same throughout the year.

\section{SUMMARY OF THE ANN IMPLEMENTATION IN SIZING A STAND-ALONE PV SYSTEM}

It can be comprehended from the previous section that ANN has been widely used in the sizing of a PV system. The ability of ANN to learn the non-linear relationship between input and output makes ANN very suitable for this purpose whether to predict the size of PV panels or PV arrays, size of batteries, solar irradiation etc. In addition, the previous section also conveys that there is a wide area of the application 
of ANN in sizing PV system that can be explore even more. These areas are explained more in the following sub-sections.

One of the most common matters that the past researchers in trying to investigate is the suitable number of neuron especially the works that have been done in $[37,40]$. This is due to the fact that there are no standard or suitable method to determine the number of neurons in the ANN. There is no guarantee that the increase number of neurons can increase the accuracy of the ANN or vice versa. Some researchers such as in [45] used 10 neurons in the hidden layer. This is because 10 number of neurons are the default neuron number in the MATLAB ANN toolbox. Many researchers have come out with a number of method in order to determine the suitable number of neurons [46-49]. The combination of GA in ANN is a good idea in order to help determining the suitable number of hidden neuron.

Another research area in this topic is the determination of the input and output of number on neurons in ANN. Similar to the determination of number of neurons, no specified method that is available on how to select which data or information as the input. Besides that, the number of inputs or set of inputs are also can be investigated in future research. As mentioned in [41], different sets of inputs will give different level of accuracy of the ANN system. So for the PV system sizing, a number of sets inputs can be prepared. Then compared these sets with the accuracy of the ANN. As far as the determination of the ANN's output is concerned, Section 4 has shown that the output can be whether any components of the PV system, the energy produced by the system, the PV panel tilt angle and the temperature of the PV panel. This area can be widen even more by including the size of other PV systems' components such as the size of charge controller and inverter.

Another research area in this topic that can be explore in future research is the improvement of the ANN configuration. This can be done by combining ANN with other artificial intelligent configuration. For instance, as discovered in [20], it is possible to combine ANN with GA. The combination of GA in ANN has shown great potential in improving the performance of the ANN. Other than GA, ANN can also be combined with fuzzy logic to create a configuration that can be called as Adaptive Neuro-Fuzzy Inference System or ANFIS. ANFIS can be defined in detailed as a structural design that consists a combination of ANN with Sugeno typed fuzzy logic. In ANFIS system, the ANN method such as back propagation is used to improve the membership functions and rules of the fuzzy system [50]. Table 1 summarizes the research area that can be done in sizing a stand-alone PV system with the application of ANN.

Table 1. Application of ANN in Sizing PV system

\begin{tabular}{|c|c|}
\hline PV sizing method & ANN application research area \\
\hline Load analysis & $\begin{array}{l}\text { Apply ANN to forecast the total number of electrical load that is used by } \\
\text { the building/house. } \\
\text { The input of the ANN can be varied. For example, the usual types and } \\
\text { rating of the electricity appliances etc. Other than that, the weather } \\
\text { condition or location can be used as a part of the inputs. }\end{array}$ \\
\hline $\begin{array}{l}\text { Determination } \\
\text { number of PV } \\
\text { panels. }\end{array}$ & $\begin{array}{l}\text { ANN can be applied to predict the required number of PV panels. } \\
\text { The input of the ANN can also be varied. Input can be taken from the } \\
\text { equation used to calculate the number of PV panels. } \\
\text { Different ANN configuration can be used and tested. }\end{array}$ \\
\hline $\begin{array}{l}\text { Sizing the size of } \\
\text { battery bank. }\end{array}$ & $\begin{array}{l}\text { ANN can be applied to predict the size. } \\
\text { The input of the ANN can also be varied. Input can be taken from the } \\
\text { equation used to calculate the size of battery bank. } \\
\text { Different ANN configuration can be used and tested. }\end{array}$ \\
\hline $\begin{array}{l}\text { Sizing other } \\
\text { components such } \\
\text { as the size of } \\
\text { inverter and solar } \\
\text { charge controller. }\end{array}$ & $\begin{array}{l}\text { ANN can be used to predict the size of inverter and solar charge controller. } \\
\text { The input of the ANN can also be varied. For example, the input from load } \\
\text { analysis can be used so that the ANN can learn the relationship between } \\
\text { load analysis and the size of inverter and solar charge controller. } \\
\text { Different ANN configuration can be used and tested. }\end{array}$ \\
\hline
\end{tabular}

\section{CONCLUSION}

This paper has presented review of the ANN methods for sizing a stand-alone photovoltaic (PV) system. The advantages of ANN especially the ability to learn the input output relationship with ample training makes ANN suitable for the PV system sizing procedures. This paper also provide information based on the review regarding the potential of the application of ANN in sizing a stand-alone PV system to be explored more in future research. The configuration, input and output of ANN definitely can be investigate more in the future in order to increase the efficiency of the ANN. From the literature review, ANN has successfully be a part of the sizing procedure by predicting the sizes of PV panels, efficiency of the PV panels, energy produced by the PV system and the tilt angle of the PV panel.

Int J Pow Elec \& Dri Syst Vol. 11, No. 1, Mar 2020 : 342 - 349 


\section{ACKNOWLEDGEMENTS}

The authors would like to Faculty of Electrical and Electronic Engineering and Universiti Tun Hussein Onn Malaysia

\section{REFERENCES}

[1] S. Eftekharnejad, V. Vittal, G. T. Heydt, B. Keel and J. Loehr, "Impact of increased penetration of photovoltaic generation on power systems," IEEE Transactions on Power Systems, vol. 28, no. 2, pp. 893-901, 2013.

[2] Y. Sun, S. Li, B. Lin, X. Fu, M. Ramezani and I. Jaithwa, "Artificial neural network for control and grid integration of residential solar photovoltaic systems," IEEE Transactions on Sustainable Energy, vol. 8, no 4, pp. 1484-1495, 2017.

[3] M. Karimi, H. Mokhlis, K. Naidu, S. Uddin and A. H. A. Bakar, "Photovoltaic penetration issues and impacts in distribution network - A review," Renewable and Sustainable Energy Reviews, vol. 53, pp. 594-605, 2016.

[4] S. R. Madeti and S. N. Singh, "A comprehensive study on different types of faults and detection techniques for solar photovoltaic system," Solar Energy, vol. 158, pp. 161-185, 2017.

[5] S. Sobri, S. Koohi-Kamali and N. A. Rahim, "Solar photovoltaic generation forecasting methods: A review," Energy Conversion and Management, vol. 156, pp. 459-497, 2018.

[6] C. Ghenai, A. Merabet, T. Salameh and E. C. Pigem, "Grid-tied and stand-alone hybrid solar power system for desalination plant," Desalination, vol. 435, no. August 2017, pp. 172-180, 2018.

[7] E. M. H. Arif, J. Hossen, G. R. Murthy, M. Z. H. Jesmeen and J. E. Raja, "An efficient microcontroller based sun tracker control for solar cell systems," International Journal of Electrical and Computer Engineering (IJECE), vol. 9, no. 4, pp. 2743-2750, 2019.

[8] L. Du, L. Zhang and Xi. Tian, "Deep power forecasting model for building attached photovoltaic system," IEEE Access, vol. 6, pp. 52639-52651, 2018.

[9] M. A. M. Ramli, A. Hiendro, K. Sedraoui and S. Twaha, "Optimal sizing of grid-connected photovoltaic energy system in Saudi Arabia," Renewable Energy, vol. 75, pp. 489-495, 2015.

[10] M. Yaichi, M.-K. Fellah and A. Tayebi, "A fast and simplified method using non-linear translation of operating points for PV modules energy output and daily pumped water to predict the performance of a stand-alone photovoltaic pumping system at different heads," Renewable Energy, vol. 133, pp. 248-260, 2019.

[11] R. Luna-Rubio, M. Trejo-Perea, D. Vargas-Va'zquez, and G. J. Rios-Moreno, "Optimal sizing of renewable hybrids energy systems : A review of methodologies," Solar Energy, vol. 86, pp. 1077-1088, 2012.

[12] W. Zhang, A. Maleki, M. A. Rosen and J. Liu, "Sizing a stand-alone solar-wind-hydrogen energy system using weather forecasting and a hybrid search optimization algorithm," Energy Conversion and Management, vol. 180, pp. 609-621, 2019.

[13] G. Jiménez-Castillo, F. J. Muñoz-Rodríguez, C. Rus-Casas, J. C. Hernández and G. M. Tina, "Monitoring PWM signals in stand-alone photovoltaic systems," Measurement, vol. 134, pp. 412-425, 2019.

[14] M. Sulaiman, A. F. M. Nor and R. Omar, "A GUI based teaching and learning software for system sizing of a stand alone hybrid solar electricity system," MAGNT Research Report, vol. 3, no. 6, pp. 72-85, 2015.

[15] T. Khatib, I. A. Ibrahim and A. Mohamed, "A review on sizing methodologies of photovoltaic array and storage battery in a standalone photovoltaic system," Energy Conversion and Management, vol. 120, pp. 430-448, 2016.

[16] S. Semaoui, A. H. Arab, S. Bacha and B. Azoui, "Optimal sizing of a stand-alone photovoltaic system with energy management in isolated areas," Energy Procedia, vol. 36, pp. 358-368, 2013.

[17] A. Mellit and M. Benghanem, "Sizing of stand-alone photovoltaic systems using neural network adaptive model," Desalination, vol. 209, pp. 64-72, 2007.

[18] A. Mellit, S. A. Kalogirou, L. Hontoria and S. Shaari, "Artificial intelligence techniques for sizing photovoltaic systems : A review," Renewable and Sustainable Energy Reviews, vol. 13, pp. 406-419, 2009.

[19] A. Mellit, "ANN-based GA for generating the sizing curve of stand-alone photovoltaic systems," Advances in Engineering Software, vol. 41, pp. 687-693, 2010.

[20] A. Mellit, S. A. Kalogirou and M. Drif, "Application of neural networks and genetic algorithms for sizing of photovoltaic systems," Renewable Energy, vol. 35, no. 12, pp. 2881-2893, 2010

[21] M. Galad and P. Spanik, "Design of photovoltaic solar cell model for stand alone renewable system," in ELEKTRO, pp. 285-288, 2014.

[22] A. El-Shahat, R. J. Haddad, B. Guha and Y. Kalaani, "Sizing residential photovoltaic systems in the state of Georgia," IEEE International Conference on Smart Grid Communications (SmartGridComm), pp. 629-634, 2015.

[23] J. P. Dunlop, "Photovoltaic Systems," 2nd ed. Illinois: American Technical Publishers, Inc., 2010.

[24] M. Ali, A. Yousaf and F. G. Seharan, "Feasibility evaluation of stand-alone photovoltaic systems for residential loads," The 9th International Renewable Energy Congress (IREC 2018), 2018, pp. 1-4.

[25] H. A. Kazem, T. Khatib and K. Sopian, "Sizing of a standalone photovoltaic/battery system at minimum cost for remote housing electrification in Sohar, Oman," Energy and Buildings, vol. 61, pp. 108-115, 2013.

[26] X. Han, X. Ai and Y. Sun, "Research on large-scale dispatchable grid-connected PV systems," Journal of Modern Power Systems and Clean Energy, vol. 2, no. 1, pp. 69-76, 2014.

[27] S. S. Mohammed, D. Devaraj and T. P. I. Ahamed, "Maximum power point Tracking system for stand alone solar PV power system using adaptive neuro-fuzzy inference system," Biennial International Conference on Power and Energy Systems: Towards Sustainable Energy (PESTSE), pp. 1-4, 2016. 
[28] V. Sharma, S. Rai and A. Dev, "A comprehensive study of artificial neural networks," International Journal of Advanced Research in Computer Science and Software Engineering, vol. 2, no. 10, pp. 278-284, 2012.

[29] R. Pagariya and M. Bartere, "Review paper on artificial neural networks," International Journal of Advanced Research in Computer Science, vol. 4, no. 6, pp. 49-54, 2013.

[30] S. Assahout, H. Elaissaoui, A. El Ougli, B. Tidhaf and H. Zrouri, "A neural network and fuzzy logic based MPPT algorithm for photovoltaic pumping system," International Journal of Power Electronics and Drive System (IJPEDS), vol. 9, no. 4, pp. 1823-1833, 2018.

[31] Sugiarti, Yuhandri, J. Na'am, D. Indra and J. Santony, "An artificial neural network approach for detecting skin cancer," TELKOMNIKA (Telecommunication Computing Electronics and Control), vol. 17, no. 2, pp. 788-793, 2019.

[32] D. Ahmed, B. Mokhtar and B. Aek, "DTC hybrid by different techniques of observation with artificial neuronal network (ANN) for induction machine drives," International Journal of Power Electronics and Drive System (IJPEDS), vol. 10, no. 2, pp. 697-708, 2019.

[33] Z.-J. Lim, M. W. Mustafa and J. J. Jamian, "Voltage stability prediction on power system network via enhanced hybrid particle swarm artificial neural network," Journal of Electrical Engineering \& Technology, vol. 10(3), pp. 877-887, 2015.

[34] H. H. Goh, Q. S. Chua, S. W. Lee, B. C. Kok, K. C. Goh and K. T. K. Teo, "Evaluation for voltage stability indices in power system using artificial neural network," Procedia Engineering, vol. 118, pp. 1127-1136, 2015.

[35] D. Q. Zhou, U. D. Annakkage and A. D. Rajapakse, "Online monitoring of voltage stability margin using an artificial neural network," IEEE Transactions on Power Systems, vol. 25, no. 3, pp. 1566-1574, 2010.

[36] L. Hontoria, J. Aguilera and P. Zufiria, "A new approach for sizing stand alone photovoltaic systems based in neural networks," Solar Energy, vol. 78, pp. 313-319, 2005.

[37] D. Baptista, S. Abreu, C. Travieso-gonzález and F. Morgado-dias, "Hardware implementation of an artificial neural network model to predict the energy production of a photovoltaic system," Microprocessors and Microsystems, vol. 49, pp. 77-86, 2017.

[38] L. M. Elobaid, A. K. Abdelsalam and E. E. Zakzouk, "Artificial neural network-based photovoltaic maximum power point tracking techniques: A survey," IET Renewable Power Generation, vol. 9, no. 8, pp. 1043-1063, 2015.

[39] I. A. Belova and M. V. Martinovich, "Neural network control algorithm for stand-alone solar cell electrical energy conversion system," 16th International Conference of Young Specialists on Micro/Nanotechnologies and Electron Devices, pp. 387-390, 2015.

[40] A. Mellit, M. Benghanem, A. H. Arab and A. Guessoum, "An adaptive artificial neural network model for sizing stand-alone photovoltaic systems: Application for isolated sites in Algeria," Renewable Energy, vol. 30, pp. 1501-1524, 2005.

[41] M. Brenna, F. Foiadelli, M. Longo and D. Zaninelli, "Solar radiation and load power consumption forecasting using neural network," 6th International Conference on Clean Electrical Power (ICCEP), pp. 726-731, 2017.

[42] I. Ceylan, E. Gedik, O. Erkaymaz and A. E. Gurel, "The artificial neural network model to estimate the photovoltaic modul efficiency for all regions of the Turkey," Energy and Buildings, vol. 84, pp. 258-267, 2014.

[43] P. Arun, "Sizing curve for isolated photovoltaic-battery systems using artificial neural networks," 2nd International Conference on Green Energy and Applications (ICGEA), pp. 147-151, 2018.

[44] A. Chatterjee and A. Keyhani, "Neural network estimation of microgrid maximum solar power," IEEE Transactions on Smart Grid, vol. 3, no. 4, pp. 1860-1866, 2012.

[45] A. F. M. Nor and M. Sulaiman, "Voltage instability analysis based on modal analysis technique and artificial neural network," Indonesian Journal of Electrical Engineering and Computer Science, vol. 13, no. 3, pp. 1274-1279, 2019.

[46] D. Hunter, H. Yu, M. S. Pukish, J. Kolbusz and B. M. Wilamowski, "Selection of proper neural network sizes and architectures - A comparative study," IEEE Transactions on Industrial Informatics, vol. 8(2), pp. 228-240, 2012.

[47] K. G. Sheela and S. N. Deepa, "Review on methods to fix number of hidden neurons in neural networks," Mathematical Problems in Engineering, vol. 2013, pp. 1-11, 2013.

[48] F. Anifowose, J. Labadin and A. Abdulraheem, "Ensemble model of artificial neural networks with randomized number of hidden neurons," 8th International Conference on Information Technology in Asia (CITA), pp. 1-5, 2013.

[49] S. Karsoliya, "Approximating number of hidden layer neurons in multiple hidden layer BPNN architecture," International Journal of Engineering Trends and Technology, vol. 3, no. 6, pp. 714-717, 2012.

[50] A. F. M. Nor, M. Sulaiman, A. F. A. Kadir and R. Omar, "Voltage stability analysis of load buses in electric power system using adaptive neuro-fuzzy inference system (ANFIS) and probabilistic neural network (PNN)," ARPN Journal of Engineering and Applied Sciences, vol. 12, no. 5, pp. 1406-1410, 2017.

Int J Pow Elec \& Dri Syst Vol. 11, No. 1, Mar 2020 : 342 - 349 


\section{BIOGRAPHIES OF AUTHORS}
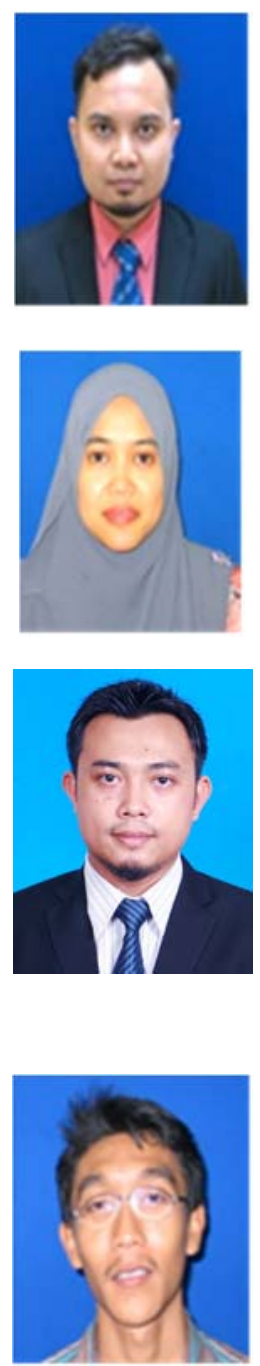

Ahmad Fateh Mohamad Nor received Bachelor of Electrical Engineering, Master of Electrical Engineering and Ph.D. in Electrical Engineering (Power) in 2011, 2013 and 2017, respectively from Universiti Teknikal Malaysia Melaka (UTeM). Currently he is a lecturer at the Department of Electrical Power Engineering, Faculty of Electrical and Electronic Engineering, Universiti Tun Hussein Onn Malaysia. His area of research interests includes electrical power engineering, voltage instability analysis, solar electricity, artificial neural network (ANN) and adaptive neurofuzzy inference system (ANFIS). He is registered as Graduate Engineer with the Board of Engineers Malaysia (BEM) as well as Graduate Technologists with the Malaysia Board of Technologists (MBOT).

Suriana Salimin is a lecturer in Faculty of Electrical Engineering (FKEE), UTHM. After graduated from her first degree in Electrical Engineering (UTM-2006), she worked as a tutor in UTHM for 6 months and continued for MSc in Power Distribution Engineering in Newcastle University (2007). She completed her $\mathrm{PhD}$ in Electrical Engineering in 2014 also from Newcastle University, UK. She has published a few papers in Journals and proceeding since 2013. Her research interests are on power quality improvement, distributed generation systems, renewable energy and harmonics mitigation. She is a member of the Institute of Electrical and Electronics Engineers (IEEE).

Mohd Noor Abdullah received his B.Eng. (Hons) in Electrical Engineering and M. Eng. in Electrical Engineering (Power System) from Universiti Teknologi Malaysia (UTM) in 2008 and 2010 respectively. He also received a Ph.D degree in Electrical Engineering from University of Malaya (UM) in 2014. He has been with Universiti Tun Hussein Onn Malaysia (UTHM) from 2008 to 2014 as a tutor. He is currently works as a lecturer in Department of Electrical Power Engineering, Faculty of Electrical and Electronic Engineering (FKEE), Universiti Tun Hussein Onn Malaysia (UTHM). He also appointed as a head of Green and Sustainable Energy (GSEnergy) Focus Group in FKEE, UTHM. He is registered as a member of Board of Engineer Malaysia (BEM) and Institute of Electrical and Electronics Engineers (IEEE). His research interests are electric power dispatch, distributed generation, renewable energy and meta-heuristic optimization techniques.

Muhammad Nafis Ismail received his B.Eng. in Electrical Engineering from Universiti Teknologi Malaysia (UTM) in 2005. He is an instructor in Faculty of Electrical Engineering (FKEE), Universiti Tun Hussein Onn Malaysia (UTHM). His area of research interests is electrical power generation. He is registered as Graduate Engineer with the Board of Engineers Malaysia (BEM). 